\title{
ATELIÊ DO SORRISO: \\ A ARTE DE ENSINAR E APRENDER EM ODONTOLOGIA
}

\begin{abstract}
Raul Elton Araujo Borges
Aluno do curso de graduação em Odontologia da Universidade Federal do Rio Grande do

Norte. E-mail: raullelton@ hotmail.com

Maurília Raquel de Souto Medeiros

Aluna do curso de graduação em Odontologia da Universidade Federal do Rio Grande do Norte. E-mail: mauriliaraquel@ hotmail.com

Iris do Céu Clara Costa

Doutora em Odontologia Preventiva e Social-UNESP-Araçatuba-SP, Pós Doutora em

Psicologia Social pela Universidade Aberta de Lisboa-PT. Coordenadora do Projeto de

Extensão Ateliê do Sorriso. Profa do Departamento de Odontologia da UFRN. E-mail.

iris_odontoufrn@yahoo.com.br
\end{abstract}

\section{RESUMO}

Introdução: A extensão universitária tem como função aproximar o mundo acadêmico da sociedade. Desse modo, o projeto de extensão Ateliê do Sorriso, criado desde 2005, tem proporcionado essa aproximação entre a população e o Departamento de Odontologia, sempre agregando conhecimento aos diversos grupos nos quais tem atuado, além de proporcionar aos alunos participantes o desenvolvimento de uma prática humanizada em saúde. Objetivo: Conhecer a opinião de participantes e ex-participantes do Ateliê do Sorriso sobre a contribuição do projeto na sua formação acadêmica. Metodologia: Foi realizada uma entrevista com todos esses alunos para verificar o seu nível de satisfação e participação, bem como a descrição dos sentimentos que desenvolveram durante sua permanência no projeto. Resultados: A entrevista demonstrou que os alunos encontram-se satisfeitos com o projeto, e que o consideram importante para sua formação acadêmica. Eles descrevem que ao mesmo tempo em que estimula o caráter educador do aluno de odontologia, contribui para uma formação multidisciplinar do cirurgião dentista de acordo com as novas diretrizes curriculares e novo perfil exigido desse profissional, de promotor de saúde e educador para além dos critérios técnicos. Conclusão: A partir dos resultados pode se dizer que o Ateliê do Sorriso aproxima a odontologia da população, proporcionando o entendimento prático do processo saúde-doença e do contexto social em que está inserida, possibilitando interação e troca de conhecimento entre alunos, de períodos diferentes do curso, além da vivência com diversas realidades socioculturais, desenvolvendo a sensibilidade social, fundamental na formação de um profissional da saúde.

PALAVRAS-CHAVE: Odontologia Preventiva; Extensão Universitária; Educação em saúde bucal; Estudantes de Odontologia.

\author{
"ATELIÊ DO SORRISO": \\ THE ART OF TEACHING AND LEARNING IN DENSTISTRY.
}




\begin{abstract}
Introduction: University extension works as a way to approximate the academic world to society. Therefore, the extension project "Ateliê do Sorriso" (Smile Studio), created in 2005, has provided this approach between the population and the Dentistry Department, always adding knowledge to the varied groups in which it has acted, besides providing the participant students the development of a humanized practice in health. Objective: To learn the opinion of participants and former participants of the "Ateliê do Sorriso" on the project's contribution to their academic backgrounds. Methodology: An interview was carried out with all of these students to check their level of satisfaction and participation, as well as a description of the feelings that was developed during their time in the project. Results: The interview showed that the students are satisfied with the project, and that they consider it important to their academic backgrounds. They describe that at the same time that it stimulates the dentistry student's educator character, it contributes to a multidisciplinary training of the dentistry surgeon according to the new curriculum guidelines and the new profile required of such a professional, of health promoter and educator beyond technical criteria. Conclusion: From the results it can be said that the "Ateliê do Sorriso" approximates dentistry to the population, providing practical understanding of the health-disease process and the social context in which it operates, enabling the interaction and exchange of knowledge among students, of different course periods, besides the experience of living different sociocultural realities, developing social sensibility, fundamental in the training of a health professional.
\end{abstract}

KEYWORDS: Preventive Dentistry, University Extension; Education in Oral Health; Dentistry Students.

\title{
ATELIÊ DO SORRISO: \\ A ARTE DE ENSINAR E APRENDER EM ODONTOLOGIA
}

\section{INTRODUÇÃO}

A extensão universitária tem como função aproximar o mundo acadêmico da sociedade, tornando acessível a população os conhecimentos de domínio da universidade. Por sua vez, as atividades de extensão foram desenvolvidas com o objetivo de reestruturação dos projetos pedagógicos na formação profissional em saúde, os quais devem responder as demandas sociais e serem capazes de instituir mudanças no quadro epidemiológico das doenças, a partir da compreensão de integralidade em saúde, buscando melhorias na qualidade de vida da população (MEDEIROS JUNIOR et al., 2005). Desta forma, cabem à extensão as responsabilidades de intervenção extramuros a partir do argumento do "compromisso social" da universidade, substitutivos da ação governamental e sob a influência do modelo de extensão cooperativa, incorporada à prática universitária como prestação de serviços. Essas atividades extensionistas contribuem para a formação de um profissional sensível as necessidades da população, baseadas na multidisciplinaridade, na integração da teoria e prática, entre ações de natureza preventiva e curativa, e principalmente entre ensino e comunidade. (COSTA et al., 2000; MOREIRA, HANH, 1992; WERNECK, LUCAS, 1996). 
Portanto, os projetos de extensão surgem como oportunidades de produção de conhecimento advindo de experiências vividas por acadêmicos em comunidades, onde se permite que o discente possa narrar sobre o seu fazer, tornando possível que outros finais ou que outros processos sejam criados, tratando-se de um espaço de integração, onde se desenvolvem estratégias de aproximação entre os diferentes sujeitos, favorecendo a consciência cidadã e humana, além de uma postura ativa e crítica da realidade que o cerca. Dessa forma, contribui para a formação de consciências politicossociais mais apuradas, não menos importantes à formação de profissionais de saúde (COSTA, ARAÚJO, 2011).

Sendo assim, tendo em vista, a grande procura no Departamento de Odontologia (DOD) da UFRN por atividades de educação em saúde, entendendo a carência dessas atividades e o perfil epidemiológico da população, o projeto de Extensão "Ateliê do Sorriso" foi criado em 2005, com o objetivo de estimular mudanças de hábitos e comportamentos de saúde bucal das clientelas assistidas, bem como, estimular a participação dos alunos de odontologia em atividades extracurriculares, estimulando-os a conhecer novas realidades fora do ambiente acadêmico. Além disso, o projeto visa divulgar conhecimentos em saúde bucal como prática eficiente de incentivo a higiene oral em diversos grupos etários e sociais, estimular a formação de educador no aluno de odontologia, contribuir para formação multidisciplinar do cirurgião dentista de acordo com as novas diretrizes curriculares e novo perfil exigido do profissional dentista.

Atualmente o Ateliê conta com a participação de aproximadamente 40 alunos, e as atividades são programadas de acordo com um calendário específico que atende tanto a demanda do público alvo, como a disponibilidade dos alunos, sendo planejada de modo a se adequar ao contexto sociocultural e a faixa etária em que será desenvolvida. Buscando sempre despertar o interesse dos participantes o "Ateliê do Sorriso" usa atividades lúdicas e interativas com o público, além de diversos recursos pedagógicos como teatro, palestras, demonstração de escovação em macro-modelos, paródias musicais, jogos, gincanas, treinamento de agentes multiplicadores de saúde, auto-exame para prevenção do câncer de boca, uso de material alternativo, material educativo destinado à pré-escolares e escolares (jogo da memória, jogo de trilha, relógio da alimentação, bingo dos alimentos, caminhos da alimentação, etc.), a idosos (bingo, damas, quebra-cabeça), panfletos, livros infantis, desenhos para colorir e outros materiais alternativos confeccionados pelos próprios alunos. Utiliza como estratégias de ação a formação de sub grupos para atuação nas instituições, realização de oficinas para confecção dos materiais educativos e reuniões mensais para monitoramento e avaliação das ações, além da troca de experiências intergrupais.

O presente trabalho descreve um relato de experiência, baseado na integração ensinocomunidade, desenvolvida no projeto de Extensão Ateliê do Sorriso com alunos de Odontologia; com vistas ao entendimento da importância e contribuição do projeto na sua vida acadêmica, bem como o período de entrada, o número de períodos que o aluno atua no projeto e a auto-avaliação quanto a sua participação.

Partindo do exposto, esse trabalho teve como objetivo conhecer a opinião de alunos participantes e ex-participantes do Ateliê do Sorriso sobre a contribuição do projeto na sua formação universitária. Portanto, descreve uma atividade de experiência extensionista, a partir da avaliação do desempenho do estudante de odontologia como educador em saúde bucal e o impacto da extensão universitária na sua formação acadêmica. 


\section{MATERIAL E MÉTODO}

Para a coleta de dados, foi utilizado um questionário auto aplicável com perguntas objetivas e subjetivas, para verificar o nível de satisfação e participação, bem como a descrição dos sentimentos que eles desenvolveram durante sua vivência no projeto. A amostra foi composta de 30 alunos, participantes e ex-participantes do referido projeto de extensão. $\mathrm{O}$ instrumento de coleta continha questões relativas ao período de entrada, há quanto tempo participa do projeto, como o estudante avalia ou avaliou sua participação e a importância das atividades de extensão universitária na sua formação acadêmica. As respostas foram analisadas quantitativamente através da estatística descritiva por meios de percentagens, representadas por gráficos e qualitativamente pelo processo de categorização das falas e análise de conteúdo das mesmas segundo Bardin (2011).

\section{RESULTADOS E DISCUSSÃO}

No que se refere ao início da participação no projeto, a figura 1 mostra que a maioria dos alunos entra cedo no Ateliê do Sorriso, o que ocorre na sua maioria por volta do terceiro período de curso. Isso acontece por ser nesse período que os alunos cursam um maior número de disciplinas no Departamento de Odontologia (DOD), o que acaba favorecendo maior interação dos alunos tendo em vista o distanciamento das disciplinas do "ciclo básico" com o "profissionalizante", associado a distância física existente entre o Campus Central e o Departamento de Odontologia. Dessa forma, só quando chegam no terceiro período é que os alunos tem mais conhecimento dos projetos desenvolvidos no departamento, tendo assim a oportunidade de se envolver nessas atividades complementares.

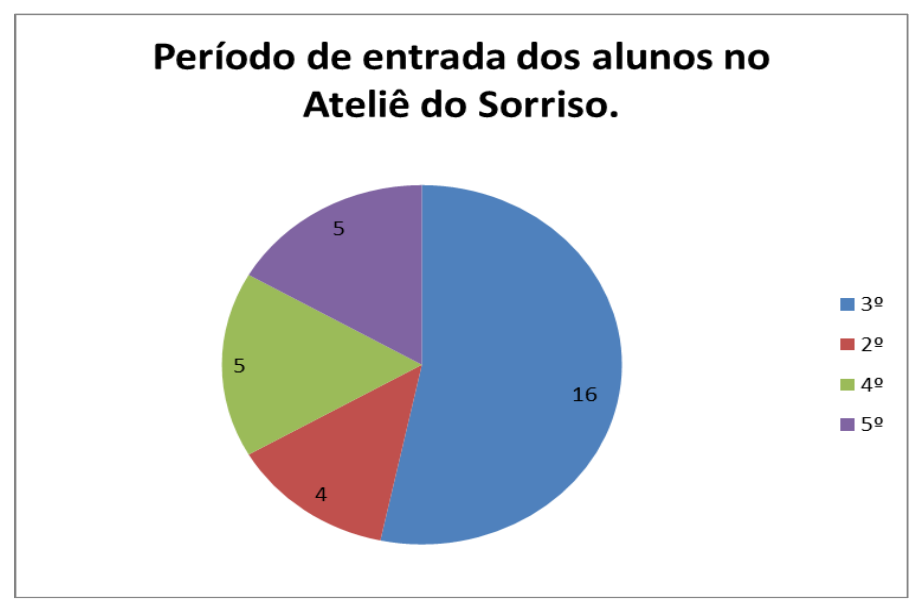

Figura 1: Período de entrada dos alunos no Ateliê do Sorriso. Natal-RN, 2013

Conforme podemos ver na figura 2, parte dos alunos (40\%) possui uma participação muito recente, cerca de apenas um semestre no Ateliê do Sorriso visto que no final do ano de 2012 houve processo seletivo para entrada no mesmo, pois muitos alunos que participavam concluíram a graduação ou entraram em outras atividades de ensino, pesquisa e extensão, abrindo oportunidades para novos interessados. 


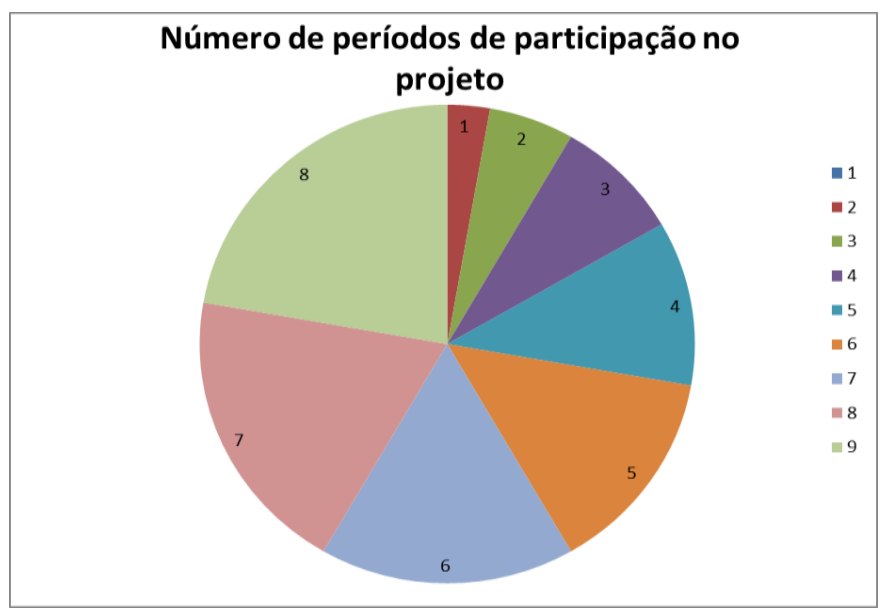

. Figura 2: Número de períodos de participação no projeto. Natal-RN, 2013

Quanto a participação de alunos em atividades de extensão, Lazzarin et al. (2010) descrevem que a maioria dos currículos dos cursos de graduação em Odontologia possui uma enorme carga horária, não havendo tempo para o estudo individualizado e muito menos para atividades complementares, intra e extramurais, como monitoria, pesquisa e extensão, essenciais para a formação em Odontologia. Apesar das dificuldades relatadas em vários estudos (MOIMAZ et al., 2004; SILVA; VASCONCELOS, 2006) sobre atividades curriculares, o presente estudo mostra que mesmo com uma carga horária extensa, podemos observar que existem alunos que estão há mais de 8 períodos participando do projeto, mostrando que é possível o desenvolvimento dessas atividades durante toda a graduação, quando o aluno se sensibiliza e a motivação pessoal supera todos os obstáculos. Importante ressaltar que quando o aluno se automotiva suficientemente ele fica por muitos períodos no projeto, mesmo que para isso tenha que sacrificar parte do seu final de semana, considerando que algumas atividades acontecem também aos sábados, uma vez que as aulas e similares preenchem todo o tempo do aluno, não restando praticamente opção para outras vivências.

No quesito avaliação, a Figura 3 mostra que os alunos têm uma avaliação positiva do Projeto analisado tendo em vista que como são formados pequenos grupos para as ações, para atuação com clientelas diversificadas todos têm a oportunidade de participar e contribuir de forma ativa no desenvolvimento das mesmas e assim aprender na prática, ao vivo, coisas sobre a solidariedade humana, sobre diferenças sociais, processos de adoecimento distintos, dentre tantas outras, que nem sempre os livros acadêmicos conseguem ensinar. Desse modo $86,6 \%$ dos entrevistados quantificaram sua participação nas atividades como boa e ótima. 


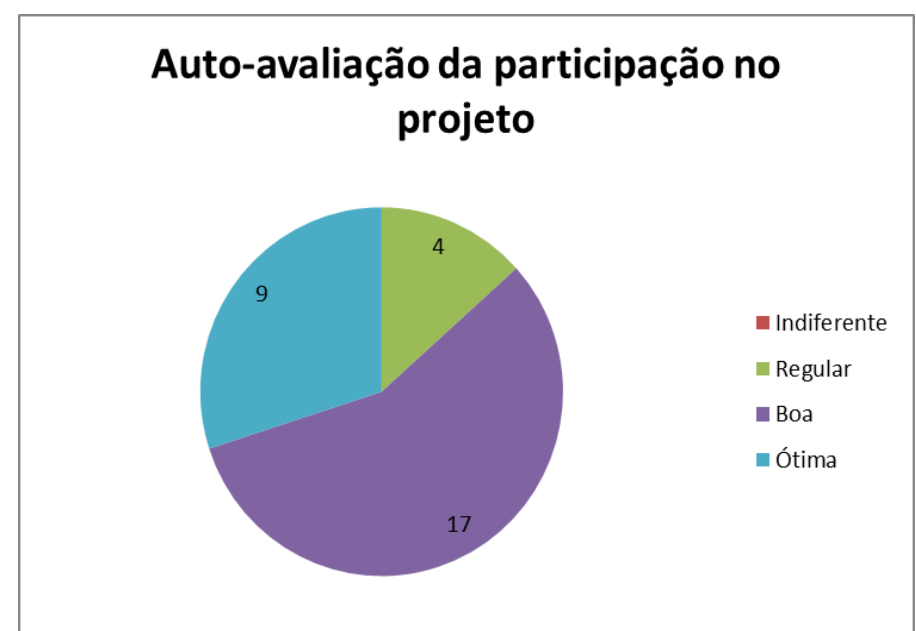

Figura 3: Auto-avaliação da participação no projeto. Natal-RN, 2013.

A esse respeito Lacerda e Ribeiro (2009) destacam em seu estudo que nos últimos anos, é perceptível por parte dos estudantes que se integram às atividades de projetos de extensão, a valorização de fazer parte de trabalhos comunitários e de assumir compromisso com a saúde da coletividade. Relata que os estudantes assumem gradualmente as atividades do projeto, não apenas no que diz respeito à sua execução, mas, também, no tocante à organização das tarefas, seu planejamento e avaliação. Com isso, todos os integrantes se sentem responsáveis pelo trabalho, conferindo maturidade, experiência e autonomia aos estudantes, dando oportunidade para que se revele o enorme potencial desses jovens.

Por sua vez, um estudo realizado por Moura et al. (2012) verificou por meio de um questionário, a opinião de 268 cirurgiões-dentistas, que participaram do projeto de extensão universitária do Curso de Odontologia da Universidade Federal do Piauí Programa Preventivo para Gestantes e Bebes-PPGB, no período de 1997 a 2011, a respeito da importância que a extensão universitária exerceu na qualificação profissional dos exestagiários. Os egressos fizeram uma avaliação positiva do PPGB como projeto de extensão e relataram que aplicam rotineiramente os conhecimentos adquiridos no mesmo, visto que muitos profissionais implantaram programas semelhantes em seus locais de trabalho. Seguindo esse raciocínio, espera-se que os participantes do Ateliê do Sorriso, também estejam aptos a desenvolver ações de promoção, prevenção, proteção e reabilitação no nível individual e coletivo, no sistema de saúde vigente e que implantem condutas semelhantes nos seus futuros espaços laborais.

Nesse contexto, os participantes e ex-participantes do Ateliê do Sorriso que compuseram nossa amostra, enfatizaram a importância do projeto na sua formação acadêmica. Corroborando a importância que os alunos referem Costa et al. (2012) descrevem que ao mesmo tempo em que estimula o caráter educador do aluno de odontologia, a extensão contribui para uma formação multidisciplinar do cirurgião dentista, bem como estimula os acadêmicos a participarem de atividades comunitárias extramuros, para que conheçam a realidade fora do ambiente acadêmico, promovendo com isso um cenário de grande aprendizado e vivência de experiências únicas durante a graduação. Além disso, esse processo coletivo de construção do conhecimento mostra a possibilidade de perspectivas atuais e futuras que contemplam a humanização e a sensibilidade social, tão necessária na formação profissional em saúde. 
Do material textual gerado a partir das perguntas subjetivas emergiram duas categorias temáticas: a primeira "importância dada à participação no Projeto" e a segunda "sentimentos vivenciados ou desenvolvidos durante o Projeto" Para ilustrar a primeira categoria apresentamos as seguintes falas.

"A extensão universitária em odontologia, proporciona uma maior abordagem da comunidade em que a universidade está inserida, além de reforçar a questão preventiva, saindo do ambiente clinico."

"É de grande importância, pois assim, podemos estar mais em contato com as pessoas, agindo diretamente, visto que no ateliê levamos a educação bucal diretamente para o público."

"A extensão nos ajuda a ter mais confiança ao transmitir nossos conhecimentos. No ateliê tive experiências únicas e gratificantes."

"A extensão universitária é de fundamental importância para formação acadêmica. Nela entramos em contato com colegas dos mais diversos períodos e todos em busca de fornecer algo de bom para a sociedade como um todo."

Para fortalecer essas falas Galassi et al. (2006) mostraram no seu estudo que através do contato com comunidades carentes de nível sócio-econômico-cultural desfavorecido e fora do ambiente formal de ensino, o aluno universitário aprende a conviver com uma realidade diferente da sua, conhecem na prática os problemas que mais acometem essas comunidades e passam a buscar as soluções que mais se adequem. Além disso, por meio das atividades de extensão, nas quais a atuação ocorre a nível grupal, o aluno aprende a atuar no âmbito da saúde coletiva, levando novos conhecimentos à população, captando dela informações e experiências, além de adquirir capacidade de comunicação, de trabalhar em conjunto e resolver conflitos, cujas habilidades para tal estão em perfeita consonância com as Diretrizes Curriculares Nacionais. Portanto, as atividades extramuros sensibilizam os alunos frente à realidade social na qual atuam, e com isso contribuem para sua formação profissional, sem contar que essas atividades vêm cumprindo com o seu papel, que é formar profissionais comprometidos com a saúde bucal coletiva (MOIMAZ et al., 2004; COSTA, ARAÚJO, 2011; COSTA et al., 2012).

Um ponto importante a ser ressaltado e que alguns autores (GALASSI et al., 2006, MOIMAZ et al. 2004; RIBEIRO, 2009; EINSFELD et al. 2009) relatam em seus estudos é o fato de que os alunos que participam de atividades de extensão durante a graduação, tornam-se mais preparados para atuar na comunidade, enquanto futuros profissionais, principalmente nos serviços de saúde, pelo fato de construírem uma consciência social comunitária, e conhecerem a diversidade cultural e social inerente ao ser humano.

Nesse sentido, Silva (2004) reitera o que outros estudos confirmaram a esse respeito: que além de conseguir superar o conhecimento puramente técnico recebido na universidade, o aluno extensionista se depara nos seus locais de atuação dos projetos, com experiências novas e muitas vezes diferentes do esperado e do vivido até então no ambiente formal da Universidade. Essas situações novas e muitas vezes inusitadas, o levam a raciocinar, mobilizar e tomar decisões, fundamentadas nos princípios básicos da humanização e 
empatia que fundamentam a educação em saúde. As falas a seguir ilustram a segunda categoria temática: "sentimentos vivenciados ou desenvolvidos durante o Projeto".

"A extensão me fez aprender a lidar com as pessoas de diferentes classes sociais, estilos de vida e também aprender a enxergar a odontologia com um olhar mais social."

"Enxergo a extensão como forma de trazer beneficios para a sociedade, e ao mesmo tempo fazer com que o profissional, desenvolva sua capacidade de interação com o paciente".

"É uma maneira de viver experiências novas e diferentes do que se vê na sala de aula".

"Uma boa oportunidade de interação com a sociedade a qual beneficia ambos os lados".

Importante ressaltar que a formação do aluno vai além da aquisição de conhecimentos técnico-científicos, até porque esses se esvaziam quando não integrados à realidade. Para uma abordagem inovadora, a aprendizagem deve ir além da aplicação imediata, estimulando o sujeito a enfrentar desafios, a interagir, entender e aceitar as diferenças, a ser capaz de gerar tecnologias e de manter a habilidade de aprender e recriar permanentemente; ou seja, a graduação deve se transformar no locus de construção/produção do conhecimento, em que o aluno atue como sujeito da aprendizagem, ensinando ao mesmo tempo que aprende, transformando pessoas, mas também se transformando, criando dessa forma uma trajetória de aprendizado para a vida (PLANO NACIONAL DE EXTENSÃO UNIVERSITÁRIA, 2001; SILVA, VASCONCELOS, 2006).

\section{CONCLUSÕES}

Após análise e discussão dos dados podemos concluir que o Ateliê do Sorriso, tem cumprido seu papel social enquanto parte de um tripé (ensino-pesquisa-extensão) que representa as dimensões sobre as quais a universidade deve fundamentar a formação dos seus alunos. Nesse contexto o Ateliê aproxima a universidade da sociedade, proporcionando o entendimento prático do processo saúde-doença, das diversas realidades, do contexto social da população trabalhada e a associação com diversas realidades socioculturais. Proporciona ao mesmo tempo a interação e troca de conhecimentos entre alunos do mesmo curso, de períodos diferentes, favorecendo um aprendizado mútuo. Além disso, favorece a troca de saberes entre alunos e sociedade, rompendo com as barreiras da formação acadêmica tecnicista, indo ao encontro da humanização do profissional e da profissão. Dessa forma, leva à população uma rede de conhecimentos muitas vezes restritos aos muros da universidade, aproxima esses conhecimentos da sua realidade, tornando-os possíveis de serem vivenciados no dia-a-dia, melhorando sua saúde e por consequência sua qualidade de vida.

É muito gratificante perceber que os participantes reconheceram a importância desse projeto e vislumbram boas perspectivas de realizar trabalhos comunitários no âmbito profissional, por compreenderem melhor os determinantes sociais no processo de adoecimento, bem como a importância da educação em saúde como estratégia de enfrentamento dessas desigualdades. Além de tudo isso, a grande procura dos alunos pelo projeto, assim como sua longa permanência ao longo do tempo, afinal são aproximadamente oito anos de existência sem interrupção, mostram que a extensão 
universitária tem avançado, considerando que os alunos têm valorizado cada dia mais suas participações em projetos dessa natureza, como complementares de sua formação acadêmica.

Conclui-se finalmente que o Ateliê do Sorriso se constitui em um espaço não apenas de troca de saberes, experiências e conhecimentos, mas também de socialização, integração e compartilhamento de vivências que ao longo dos anos vem contribuindo para a compreensão e empoderamento da saúde pelos alunos do curso de odontologia e pela população.

\section{REFERÊNCIAS BIBLIOGRÁFICAS}

1. BARDIN, L. Análise de conteúdo. São Paulo: Edições 70, 2011, 229p.

2. BRASIL. Secretaria de Educação Superior. Plano Nacional de Extensão. Brasília, DF, 2007. Disponível em: 〈http://portal.mec.gov.br/sesu >. Acesso em : 15 de out de 2013

3. COSTA, I. C. C. et al. Ateliê do sorriso: espaço de troca de saberes e vivências compartilhadas. Extensão e Sociedade, v. 1, n. 5, p. 15-28, 2012.

4. COSTA, I. C. C. et al. Integração universidade-comunidade: análise das atividades extra-murais em odontologia nas universidades brasileiras. Rev. Cons. Reg. Odontol. Minas Gerais, v. 3, n. 6, p. 146-53, 2000.

5. COSTA, I. C. C.; ARAÚJO, M. N. T. Definição do perfil de competências em saúde coletiva a partir da experiência de cirurgiões-dentistas. Ciência e Saúde Coletiva (Impresso), v. 16, p. 1181-1189, 2011.

6. EINSFELD, L. et al. A extensão universitária enquanto ferramenta para formação de um novo perfil de profissional farmacêutica. Em Extensão, Uberlândia, v. 8, n. 2, p. 23 - 32, ago./dez., 2009.

7. GALASSI, M. A. S. et al. Atividades extramuros como estratégia viável no processo ensino-aprendizagem. Revista da ABENO, v. 6, n. 1, p. 66-69, 2006.

8. LACERDA, D. A. L.; RIBEIRO, K. S. Q. S. A história de uma experiência da fisioterapia em um projeto de extensão comunitária. In: LACERDA, D. A. L.; RIBEIRO, K. S. Q. S (Org.). Fisioterapia na comunidade: uma experiência na atenção básica. João Pessoa: UFPB, 2006. p. 91-108.

9. LAZZARIN, H. C. O papel do professor no processo ensino-aprendizagem: percepção de professores e alunos de odontologia. 147 f. 2005. Dissertação (Mestrado em Saúde Coletiva) Departamento de Saúde Coletiva, Universidade Estadual de Londrina, Londrina, 2005.

10. MEDEIROS JÚNIOR, A. et al. Experiência extramural em hospital público e a promoção da saúde bucal coletiva. Rev. Saúde Pública, v. 39, n. 2, p. 305-310, 2005. 
11. MOIMAZ, S. A. S. et al. Serviço extramuro odontológico: impacto na formação profissional. Pesq. Bras. Odontoped. Clin. Integr., João Pessoa, v. 4, n. 1, p. 53-57, jan./abr., 2004.

12. MOREIRA, S. G.; HANH, M. A. S. Considerações sobre trabalho educativopreventivo a nível comunitário. Rev. Fac. Odontol. Porto Alegre, v. 1, n. 33, p. 267, 1992.

13. MOURA, L. F. A. D. et al. Impacto de um projeto de extensão universitária na formação profissional de egressos de uma universidade pública. Rev. Odontol. UNESP, v. 41, n. 6, p. 348-352, 2012.

14. RIBEIRO, K. S. Q. S. A experiência na extensão popular e a formação acadêmica em Fisioterapia. Cad. Cedes, Campinas, v. 29, n. 79, p. 335-346, set./dez., 2009.

15. SILVA, A. A. S. O programa UFBA em campo - ACC: sua contribuição na formação do estudante. Rev. Faced, Salvador, n. 13, p. 83-102, 2004.

16. SILVA, M. S., VASCONCELOS, S. D. Extensão universitária e formação profissional: avaliação da experiência das ciências biológicas na Universidade Federal de Pernambuco. Estudos em Avaliação Educacional, v. 17, n. 33, jan./abr., 2006.

17. WERNECK, M. A. F.; LUCAS, S. D. Estágio supervisionado em odontologia: uma experiência da integração ensino/serviço de saúde bucal. Arq. Centro Estud. Fac. Odontol. Minas Gerais, v. 2, n. 32, p. 95-108, 1996. 